\title{
Coronary Stent Implantation in Diabetic versus Nondiabetic Patients. Early and Late Outcomes
}

\author{
Denis M oulin Bayerl, Erasmo Siqueira, Isaac M oscoso, Elise Santos, A lexandre Maeda, O scar \\ Bittencourt, M. Fernanda Mauro, Salvador Cristovão, Adnan Salman, Gustavo Sanches, \\ José Armando Mangione
}

São Paulo - SP - Brazil

\begin{abstract}
Objective - To assess whether coronary stenting in diabetic patients provides in-hospital results and clinical evolution similar to those in nondiabetic patients.

Methods - From July '97 to April '99 we performed coronary stent implantation in 386 patients with coronary heart disease, who were divided into two groups: diabetic patients and nondiabetic patients. The in-hospital results and the clinical evolution of each group were retrospectively analyzed.
\end{abstract}

Results - The nondiabetic group comprised 305 (79\%) patients and the diabetic group 81 (21\%) patients. Basic clinical and angiographic characteristics were similar. Angiographic success was in diabetics $=96.6 \% \mathrm{vs}$ in nondiabetics $=97.9 \%(p=n s)$. Among the major complications in the in-hospital phase, the rate of myocardial infarction was higher in the diabetic group $(7.4 \%$ vs $1.9 \%)$ $(p=0.022)$. In the follow-up, a favorable and homogeneous evolution occurred in regard to asymptomatic patients, myocardial infarction, and death in the groups. A greater need for revascularization, however, existed in the diabetic patients ( $15 \%$ vs $2.4 \%, p<0.001)$.

Conclusion - Coronary stenting in diabetic patients is an efficient procedure, with a high angiographic and clinical success rate similar to that in nondiabetic patients. Diabetic patients, however, had a higher incidence of in-hospital myocardial infarction and a greaterneed for additional myocardial revascularization.

Key words: diabetes mellitus, coronary artery disease, coronary stent

Hospital São Joaquim da Real e Benemérita Sociedade Portuguesa de Beneficência Mailing address: Denis Moulin Bayerl - Rua Maestro Cardim, 769 - 1 Subsolo, B1. I - S/71 - 01323-900 - São Paulo, SP, Brazil

English Version by Stela Maris C. Gandour
Diabetes mellitus and atherosclerosis have a reciprocal relation as diabetes is one of the major risk factors for the development of atherosclerosis, which is the major cause of mortality in this group of patients.

Studies based on pathological and angiographic evidence ${ }^{1,2}$ show a higher severity and extension of the coronary atherosclerotic disease in diabetic patients with a consequent unfavorable clinical evolution in the long-term.

Controversies in regard to the best strategy for myocardial revascularization in diabetic patients still occur. Percutaneous intervention through balloon catheter angioplasty has some disadvantages such as a smaller capacity for complete revascularization due to the unfavorable angiographic profile and the high incidence of restenosis resulting in high morbidity and late mortality ${ }^{3-5}$.

In this context, coronary stenting is a useful therapeutical option because it not only reduces the incidence of restenosis and allows a more complete revascularization, but also facilitates the approach of more complex lesions with greater safety and a lower rate of complications ${ }^{6,7}$.

Our study aims to assess in-hospital results and the late clinical outcome of diabetic and nondiabetic patients undergoing coronary stenting.

\section{Methods}

In our service at the Hospital da Beneficência Portuguesa de São Paulo, 430 stents were implanted in 386 patients from July '97 to April ' 99 . The nondiabetic group comprised $305(79 \%)$ patients who received 340 stents, and the diabetic group comprised $81(21 \%)$ patients, $12(14.8 \%)$ of whom were insulin-dependent patients, receiving 90 stents. The mean age was 61 years, and males prevailed in both groups (Table I).

We included patients who underwent stent implantation, with of stable or unstable angina, and acute myocardial infarction. The groups were homogeneous in regard 
to demographic and basic clinical characteristics (Table I). In both groups, the prevailing clinical status was unstable angina, and in the nondiabetic group asymptomatic patients predominated (Table I).

Three days prior to the procedure, when clinically possible, the patients received $500 \mathrm{mg} /$ day of ticlopidine and $200 \mathrm{mg} /$ day of acetylsalicylic acid for 30 days and during the entire period of follow-up, respectively. In the catheterization laboratory, after selective catheterization of the coronary artery, 10,000 $\mathrm{U}$ of heparin were administered into the coronary artery.

Stents were implanted after conventional balloon catheter angioplasty of the target lesion, using final pressures routinely $\geq 10$ atmospheres.

Angiographic success was defined as residual lesion $<20 \%$ in the presence of TIMI III flow, and the clinical success was defined as the angiographic success in the absence of major complications (acute myocardial infarction, need for emergency myocardial revascularization, and death). Major vascular complications were defined as those complications requiring surgical repair at the site of puncture or bleeding with a hemoglobin level fall $>5 \mathrm{~g} / \mathrm{dL}$.

The percentage stenosis and the minimum and reference luminal diameters of the artery were analyzed before and immediately after the procedure through quantitative digital angiography, using the online system Toshiba DEF 1000A.

Clinical follow-up was performed through out patient visits, direct telephone contact with the patient, or with the assistant physician.

Continuous variables were expressed as mean and standard deviation and assessed using the paired and nonpaired Student $t$ tests. Categorical variables presented as percentages were analyzed through the chi-square test. A p value $<0.05$ was considered significant.

\section{Results}

Angiographic and clinical successes were similar:

\begin{tabular}{|c|c|c|c|}
\hline \multicolumn{4}{|c|}{ Table I - Demographic and clinical data } \\
\hline & $\begin{array}{c}\text { DM } \\
(\mathrm{n}=81)\end{array}$ & $\begin{array}{c}\text { NDM } \\
(\mathrm{n}=305)\end{array}$ & $\mathrm{P}$ \\
\hline Age & $61.8 \pm 11.3$ & $61.3 \pm 12.4$ & NS \\
\hline Sex & $54(67 \%)$ & $222(73 \%)$ & NS \\
\hline Hypertension & $59(73 \%)$ & $192(63 \%)$ & NS \\
\hline Dyslipidemia & $45(56 \%)$ & $137(45 \%)$ & NS \\
\hline Smoking & $13(16 \%)$ & $91(30 \%)$ & 0,07 \\
\hline Familial history & $37(46 \%)$ & $168(55 \%)$ & NS \\
\hline Previous TCA & $11(14 \%)$ & $6(12 \%)$ & NS \\
\hline Previous AMI & $16(20 \%)$ & $88(29 \%)$ & NS \\
\hline Previous surgery & $14(18 \%)$ & $55(18 \%)$ & NS \\
\hline Unstable angina & $54 \%$ & $48 \%$ & NS \\
\hline Stable angina & $26 \%$ & $21 \%$ & NS \\
\hline Asymptomatic & $13 \%$ & $20 \%$ & 0,088 \\
\hline AMI & $07 \%$ & $11 \%$ & NS \\
\hline
\end{tabular}

$96.6 \%$ and $97.9 \%$, respectively, for the diabetic group, and $92.6 \%$ and $96.4 \%$, respectively, for the nondiabetic group $(\mathrm{p}=\mathrm{ns})$.

Angiographic characteristics were similar in regard to the artery treated, complexity, and length of the lesions (Table II). A quantitative digital analysis showed no differences, except in the minimum luminal diameter after the procedure, which tended to be smaller in the diabetic group (Table III).

During the in-hospital evolution, the diabetic group showed a higher rate of acute myocardial infarction $7.4 \% \mathrm{vs}$ $1.9 \%$ ( $\mathrm{p}=0.022$ ), (fig. 1) in spite of having a similar incidence of $Q$ and non-Q acute myocardial infarctions when separately analyzed (Table IV). No emergency myocardial revascularization was required, and $2(0.6 \%)$ patients in the nondiabetic group died due to subacute thrombosis of the stent. Major vascular complications were also similar in both groups (Table IV).

In the diabetic group, the mean clinical follow-up was $10.8 \pm 6.12$ months, and it was performed in $73(90 \%)$ patients. In the nondiabetic group, the mean clinical follow-up was $11.08 \pm 6.31$ months $(\mathrm{p}=\mathrm{ns})$, and it was performed in 287 (94\%) patients. No difference was observed in the incidence of asymptomatic patients $(90.4 \%$ vs $93 \%)$ or in the inci-

\begin{tabular}{|c|c|c|c|}
\hline \multicolumn{4}{|c|}{ Table II - Angiographic characteristics } \\
\hline Vessel treated & $\begin{array}{c}\mathrm{DM} \\
(\mathrm{n}=90)\end{array}$ & $\begin{array}{c}\text { NDM } \\
(n=340)\end{array}$ & $\mathrm{p}$ \\
\hline $\mathrm{AD}$ & $38 \%$ & $37 \%$ & NS \\
\hline $\mathrm{RC}$ & $33 \%$ & $31 \%$ & NS \\
\hline NS & $10 \%$ & $11 \%$ & NS \\
\hline SVBG & $14 \%$ & $15 \%$ & NS \\
\hline \multicolumn{4}{|l|}{ Type of lesion } \\
\hline A & $04 \%$ & $04 \%$ & NS \\
\hline B1 & $29 \%$ & $24 \%$ & NS \\
\hline B2 & $38 \%$ & $34 \%$ & NS \\
\hline $\mathrm{C}$ & $29 \%$ & $32 \%$ & NS \\
\hline \multicolumn{4}{|l|}{ Length } \\
\hline$<10 \mathrm{~mm}$ & $21 \%$ & $24 \%$ & NS \\
\hline between 10 e $20 \mathrm{~mm}$ & $47 \%$ & $53 \%$ & NS \\
\hline$>20 \mathrm{~mm}$ & $32 \%$ & $24 \%$ & NS \\
\hline \multicolumn{4}{|c|}{$\begin{array}{l}\text { DM- diabetes mellitus; NDM- nondiabetic; LAD - left anterior descen- } \\
\text { ding coronary artery; RC - right coronary artery; } \mathrm{CX} \text { - circumflex coronary } \\
\text { artery; SVBG- saphenous vein bypass graft. }\end{array}$} \\
\hline
\end{tabular}

\begin{tabular}{|lccc|}
\hline \multicolumn{4}{|c|}{ Table III - Data from quantitative digital angiography } \\
\hline & $\begin{array}{c}\mathrm{DM} \\
(\mathrm{n}=90)\end{array}$ & $\begin{array}{c}\mathrm{NDM} \\
(\mathrm{n}=340)\end{array}$ & $\mathrm{P}$ \\
\hline & $3.09 \pm 0.42$ & $3.15 \pm 0.54$ & $\mathrm{NS}$ \\
Pre RLD (mm) & $0.80 \pm 0.48$ & $0.88 \pm 1.64$ & $\mathrm{NS}$ \\
Pre MLD (mm) & $3.20 \pm 0.39$ & $3.29 \pm 0.30$ & 0.064 \\
Post MLD (mm) & $89.3 \pm 8.87$ & $88.4 \pm 10.7$ & $\mathrm{NS}$ \\
$\%$ stenose pre & $1.30 \pm 8.37$ & $2.03 \pm 10.7$ & $\mathrm{NS}$ \\
$\%$ stenose pos & \multicolumn{3}{l}{} \\
\hline $\begin{array}{l}\text { DM- diabetes mellitus; NDM- nondiabetic; RLD- reference luminal } \\
\text { diameter; MLD- minimum luminal diameter; "pre" refers to prior to the }\end{array}$ \\
procedure; "post" refers to after the procedure \\
\hline
\end{tabular}




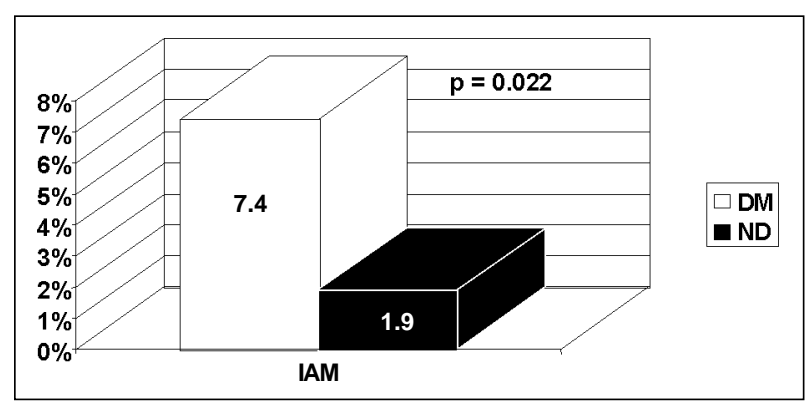

Fig.1 - In-hospital results.

\begin{tabular}{|lccc|}
\hline \multicolumn{4}{|c|}{ Table IV - Incidence of in-hospital complications } \\
\hline & $\mathrm{DM}$ & $\mathrm{NDM}$ & $\mathrm{P}$ \\
& $(\mathrm{n}=81)$ & $(\mathrm{n}=305)$ & \\
\hline Any AMI & $7,4 \%$ & $1,9 \%$ & 0.022 \\
Q AMI & $2,5 \%$ & $0,6 \%$ & $\mathrm{NS}$ \\
Non-Q AMI & $4,9 \%$ & $1,3 \%$ & $\mathrm{NS}$ \\
Emergency MR & 0 & 0 & $\mathrm{NS}$ \\
Death & 0 & $0,6 \%$ & $\mathrm{NS}$ \\
Vascular complications & $6,1 \%$ & $7,8 \%$ & \\
\hline
\end{tabular}

DM- diabetes mellitus; NDM- nondiabetic; AMI- acute myocardial infarction; MR- myocardial revascularization.

dence of patients with stable angina (6.8\% vs 5.0\%) and unstable angina $(2.7 \%$ vs $1.3 \%)$ between the diabetic and nondiabetic groups, respectively. Rates of acute myocardial infarction and death were also similar; the diabetic group, however, required more myocardial revascularization ( $15 \%$ vs $2.4 \%)(\mathrm{p}<0.001)$. This directly influenced the occurrence of major cardiac events in the diabetic group $(\mathrm{p}<0.0001)$ (fig. 2).

\section{Discussion}

The presence of diabetes mellitus in patients with coronary atherosclerotic disease is a marker of poor prognosis, representing a challenge to clinicians, intervention cardiologists, and cardiac surgeons.

The metabolic and endothelial changes present in diabetic patients and the higher chance of rupture of the plaque, thrombus formation, and exacerbation of the intimal hyperplasia are determinant factors of a higher incidence of complications and restenosis in these patients when they

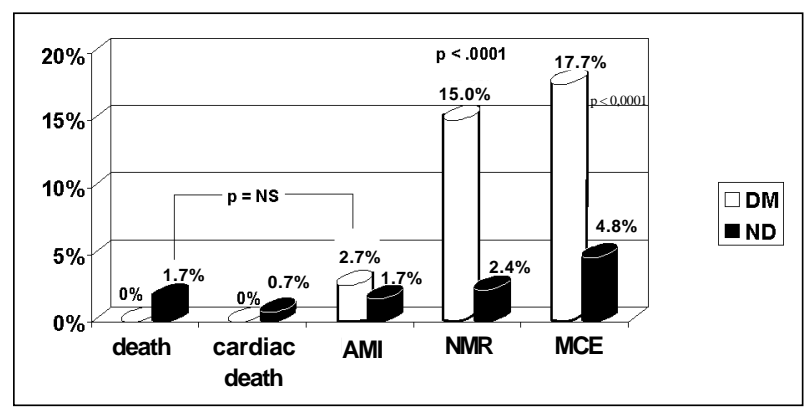

Fig. 2-NMR - need for myocardial revascularization; MCE-major cardiac events. undergo percutaneous coronary interventions ${ }^{4,8,9-11}$. In addition, diabetic patients have more severe angiographic and clinical profiles and usually have associated diseases, such as hypertension, dyslipidemia, coagulopathies, and nephropathies, therefore requiring a strict control because these factors influence the occurrence of cardiovascular events during follow-up ${ }^{12,13}$.

Randomized studies, such as BARI ${ }^{14}$ and CABRI ${ }^{15}$, in patients with multivessel lesions have shown a higher survival rate for diabetic patients undergoing surgery, as compared with those treated with coronary balloon angioplasty. The EAST study ${ }^{16}$, however, has shown no difference in patient survival at the end of 5 years for both procedures.

Another study ${ }^{17}$ recently published analyzing patients who met the criteria for randomization but who did not take part in the BARI Study has shown a similar mortality rate for diabetic patients undergoing balloon catheter angioplasty and surgery. Some distinct basic and angiographic characteristics were observed in the diabetic control group when compared with the randomized group, as follows: higher degree of education, better quality of life, lower incidence of smoking, and lower degree of left ventricular dysfunction. They also reported that in the control group, the diabetic patients undergoing balloon catheter angioplasty had a lower incidence of triple vessel coronary atherosclerotic disease when compared with the group undergoing surgery.

The role played by coronary stents in the treatment of diabetic patients has not been totally established. In our study, where we report our experience with coronary stenting, we observed a high rate of clinical and angiographic success for both groups. In the in-hospital phase, however, the incidence of major cardiac events was higher in the diabetic group, basically due to a higher incidence of acute myocardial infarction in this group. This may be explained by the higher predisposition to rupture of the atheromatous plaque in these patients with consequent formation of a platelet thrombus, in addition to changes in the coagulation system ${ }^{1,2,3,7,8,13}$. It is worth stressing that emergency myocardial revascularization was not required for any group, showing the efficiency of stenting in this context.

Clinical follow-up showed a favorable evolution because more than $90 \%$ of the patients of both groups were asymptomatic. The same occurred with the incidence of acute myocardial infarction and late deaths, but more myocardial revascularizations were required in the diabetic group. Studies by Tilli et al ${ }^{18}$, Kastrati et al ${ }^{19}$, and Abizaid et $\mathrm{al}^{20}$ have shown a need two times greater for revascularization of the target lesion (RTL) by the end of 6 months in diabetic patients undergoing stenting. Its employment, however, shows a clear superiority in relation to the primary success, clinical evolution, and rate of restenosis, as compared with conventional balloon catheter angioplasty ${ }^{21-23}$.

More recently, the use of adjunctive pharmacological therapy, mainly inhibitors of the receptors of platelet glycoprotein IIb/IIIa, has shown additional benefit in the percutaneous treatment of diabetic patients, as shown in the EPIS- 
TENT Study ${ }^{24}$. In this study, administration of abciximab associated with coronary stenting caused a $50 \%$ reduction in the need for RTL in that group of patients by the end of 6 months, and this benefit remained after one year, evolving in a manner similar to that of nondiabetic patients.

We believe, as reported by Centemero et $\mathrm{al}^{25}$, that the mere presence of diabetes mellitus should not determine the type of revascularization (percutaneous or surgical). Other factors should be considered as follows: presence of associated comorbidities; type of clinical presentation of the diabetes; patient's age; morphological and angiographic characteristics of the lesions; extension of the coronary atherosclerotic disease; presence of ventricular dysfunction; and the social, economical, and cultural level of the patient.

Finally, we should await the conclusion of randomized studies (ARTS, SOS), which including the analysis of subgroups, such as diabetic patients, will provide important in- formation about the efficacy of stent implantation versus surgery in patients with multivessel lesions.

The recent ARTS Study ${ }^{26}$ comparing the efficacy of stenting versus surgery in patients with multivessel lesions has shown a higher incidence of patients free from compound events (death, myocardial infarction, surgery, or rePTCA) in the surgical group by the end of one year $(87.8 \%$ vs $73.7 \%$; $<0.001)$. This difference basically results from a greater need for a new angioplasty in the group undergoing the percutaneous procedure. Analysis of the diabetic subgroup, however, has shown that a greater difference favoring the surgical group exists $(82.3 \%$ vs $60.7 \%, \mathrm{p}<0.001)$ and that the isolated use of stents in diabetic patients with multivessel lesions is not enough to optimize the results. The ARTS Study has also stressed the importance of the adjunctive pharmacological therapy with inhibitors of PG IIb/IIIa in the percutaneous approach of these patients.

\section{References}

1. Ledet T. Histological and histochemical changes in the coronary arteries of old diabetic patients. Diabetologia 1968; 4: 268-72.

2. Vigorita VJ, Moore GW, Huthins GM, et al. Absence of correlation between coronary arterial atherosclerosis and severity or duration of diabetes mellitus of adult onset. Am J Cardiol 1980; 46: 535-42.

3. Ellis SG, Vandormael MG, Cowley MJ, et al. Coronary morphologic and clinical determinants of procedural outcome with angioplasty for multivessel coronary disease: implications for patient selection. Circulation 1990; 82: 1193-202.

4. Weintraub WS, Kasinsky AS, Brown CL, et al. Can restenosis after coronary angioplasty be predicted from clinical variables? J Am Coll Cardiol 1993; 21: 6-14.

5. Willian W, O'Neill FACC. Multivessel Balloon Angioplasty should be abandoned in Diabetic patients! J Am Coll Cardiol 1998; 31: 20-2.

6. Abizaid A, Kornowski R, Mintz G, et al. The influence of diabetis mellitus on acute and late outcomes following coronary stent implantation. J Am Coll Cardiol 1998; 32: 584-9.

7. Chaves A, Centemero MP, Pinto I. Diabetes mellitus e evolução pós implante de stents coronarianos. Rev Soc Cardiol ESP 1997; 7(supl B): B-36.

8. Aronson D, Bloomgaredn Z, Nayfield EJ. Potential mechanisms promoting restenosis in diabetic patients. J Am Coll Cardiol 1996; 27: 528-35.

9. Carrozza JP, Kuntz RE, Fishman F, et al. Restenosis after injury caused by coronary stenting in patients with diabetes mellitus. Ann Intern Med, 1993; 118: 344-9.

10. Kornowsky R, Mintz GS, Kent KM, et al. Increased restsnosis in diabetes mellitus after coronary intervention is due to exaggerated intimal hyperplasia. Circulation 1997; 95: 1366-9.

11. Stein B, Weintraub WS, Gebhart S, et al. Influence of diabetes mellitus on early and late outcome after percutaneous transluminal coronary angioplasty. Circulation 1995; 91: 979-89.

12. Sowers JR, Epstein M. Diabetes mellitus and associated hypertension, vascular disease, and nephropaty. Hypertension 1995; 26: 869-79.

13. Webster MW, Scott RS. What cardiologists need know about diabetes. Lancet 1997; 350: 23-7.

14. The Bypass Angioplasty Revascularization Investigation (BARI) Investigators. Comparison of coronary bypass surgery with angioplasty in patients with multivessel disease. N Engl J Med 1996; 335: 217-25.
15. CABRI Trial Participants. Coronary Angioplasty versus Bypass Revascularization Investigations (CABRI): results during the first year. Lancet 1995; 346 : 1179-83.

16. Weintraub WS, Boccuzzi S, Morris DC, et al. Coronary surgery and coronary angioplasty in diabetics: diet therapy, oral hypoglycemics and insulin. Circulation 1997; 96(suppl I): I-23.

17. Detre KM, Guo P, Holubkov R, et al. Coronary revascularization in diabetic patients. a comparison of the randomized and observational components of the Bypass Angioplasty Revascularization Investigation (BARI). Circulation 1999; 99: 633-40.

18. Tilli FV, Aliabadi D, Bowers T, et al. Optimal coronary stenting in diabetics: available percutaneous alternative to cardiac surgery. J Am Coll Cardiol 1997; 29(suppl A): A-455.

19. Kastrati A, Schoming A, Elezi S, et al. Predictive factors of restenosis after coronary stent placement. J Am Coll Cardiol, 1997; 30: 1428-36.

20. Abizaid A, Mehran R, Bucher TA, et al. Does diabetes influence clinical recurrence after coronary stent implantation? J Am Coll Cardiol 1997; 29(suppl-A): A-188.

21. Savage MP, Fischman DL, Slota P, et al. Coronary intervention in the diabetic patient: improved outcome following stent implantation versus balloon angioplasty. J Am Coll Cardiol 1997; 30: 1428-36.

22. Van Belle E, Bauters C, Hubert E, et al. Angiographic follow-up after coronary stenting or balloon angioplasty in diabetic patients. Circulation 1997; 96(suppl I): I-323.

23. Van Belle E, Bauters C, Hubert E, et al. Restonosis rates in diabetic patients. A comparison of coronary stenting and balloon angioplasty in native coronary vessels. Circulation 1997; 96: 1454-60.

24. EPISTENT Investigators. Randomised placebo-controlled and balloon-angioplasty-controlled trial to asses safety of coronary stenting with use of platelet glycoprotein-IIb/IIIa blockade. Lancet 1998; 352: 87-92.

25. Centemero M, Sousa AGMR, Chaves A, et al. Revascularização percutânea no paciente diabético. Rev Soc Cardiol ESP 1998; 8: 936-45.

26. Borness GW, Peterson ED, Ohman EW, et al. Relationship between diabetes mellitus and long-term survival after bypass and angioplasty. Circulation 1997; 96: 2551-5. 